\title{
Article
}

\section{Helmholtz Resonance Frequency of the Synthetic Jet Actuator}

\author{
Paweł Gil ${ }^{1, * \mathbb{D}}$, Joanna Wilk ${ }^{1}$ and Michał Korzeniowski ${ }^{2}$ \\ 1 Department of Thermodynamics, Faculty of Mechanical Engineering and Aeronautics, Rzeszow University of \\ Technology, al. Powstańców Warszawy 12, 35-959 Rzeszów, Poland; joanwilk@prz.edu.pl \\ 2 Department of Electrical and Computer Engineering Fundamentals, Faculty of Electrical and Computer \\ Engineering, Rzeszow University of Technology, al. Powstańców Warszawy 12, 35-959 Rzeszów, Poland; \\ mkorzen@prz.edu.pl \\ * Correspondence: gilpawel@prz.edu.pl
}

check for

updates

Citation: Gil, P.; Wilk, J.; Korzeniowski, M. Helmholtz Resonance Frequency of the Synthetic Jet Actuator. Appl. Sci. 2021, 11, 5666. https://doi.org/10.3390/app11125666

Academic Editor: Jan Awrejcewicz

Received: 19 May 2021

Accepted: 15 June 2021

Published: 18 June 2021

Publisher's Note: MDPI stays neutral with regard to jurisdictional claims in published maps and institutional affiliations.

Copyright: (c) 2021 by the authors. Licensee MDPI, Basel, Switzerland. This article is an open access article distributed under the terms and conditions of the Creative Commons Attribution (CC BY) license (https:// creativecommons.org/licenses/by/ $4.0 /)$.

\begin{abstract}
This paper presents the results of experimental investigations of 108 geometrical configurations of a loudspeaker-driven synthetic jet (SJ) actuator. The considered cases of the SJ actuator were characterized by a high coupling ratio. The experiment was performed to determine the impact of geometry on the Helmholtz resonance frequency. Geometrical parameters of the orifice diameter, orifice length, and cavity volume were changed within a wide range. The dependences of electrical and flow parameters that characterized the synthetic jet actuators as a function of the excitation frequency were also identified. The main goal of the research was to identify the optimal mathematical formula of the model to calculate the Helmholtz resonance frequency in the case of synthetic jet actuators. To determine the model that was characterized by the best fit of the experimental results, an additional geometrical dimensionless parameter, representing the ratio of the orifice cross-section area to the cross-section area of the cavity, was introduced. A significant impact of this parameter on the effective orifice length was noted. Based on the research findings, a model was obtained for which the results of the experiment were in the error range of $\pm 6 \%$ for $95 \%$ of the measurement data. The obtained model is an improved version of the classical model used in the description of the resonance frequency in the case of a synthetic jet actuator. The model enables highly accurate determination of the Helmholtz resonance frequency at which the maximum synthetic jet actuator parameters occur.
\end{abstract}

Keywords: synthetic jet; Helmholtz resonance frequency; effective orifice length; frequency response

\section{Introduction}

A typical synthetic jet actuator (SJA) is a zero-net mass-flux device. A synthetic jet (SJ) is directly formed by the fluid system in which the synthetic jet actuator is located. The SJ is produced by the interaction of a train of vortices that are formed by successive suction and ejection of the fluid across an orifice. The working fluid is alternately sucked into and ejected from the cavity by the motion of a diaphragm that bounds the cavity. Cavity volume oscillation may be caused by a loudspeaker or piezoelectric actuator. The case in which a loudspeaker is used is the subject of the present work.

A synthetic jet is a novel flow technique that may be useful for cooling applications, among others, in electronic systems. Recently, synthetic jets have been extensively studied. A number of positions can be found in the literature regarding properties and applications of SJs. The latest references include, among others, the review articles [1,2], in which the authors present a detailed overview of SJ characteristics and parameters that can influence the enhancement of fluid flow and heat transfer. In addition, research on the acoustic and flow properties of an SJ actuator driven by a loudspeaker was recently conducted in $[3,4]$.

It should be emphasized that the literature cited above represents only a small portion of the total volume of SJ research, which began at the end of the last century [5-7].

The frequency characteristics are among the SJ topics studied. A synthetic jet actuator with a single cavity and one orifice is characterized by two resonance frequencies: the first 
resulting from the properties of the actuator and the second resulting from the Helmholtz resonance system. These frequencies were the subject of the research of Guy et al. [8,9], in which the authors showed that the output of the actuator is maximized at the two resonance frequencies considered. Consequently, the SJ actuator energetic efficiency is also maximized at the resonance frequency, as reported by Gil and Smyk in [10]. Investigations on flow characteristics of $\mathrm{SJ}$ in connection with resonance frequencies have been performed by, among others, Chaundhari et al. [11], Gil and Strzelczyk [12], Kordik [13], Gallas et al. [14-16], and Sharma et al. [17,18]. It has been concluded that the characteristic SJ velocities are also maximized at the resonance frequencies. Due to the application of SJs in cooling systems, the heat transfer intensity is an important issue in SJ investigations. The results of the conducted research show that excitation frequencies have an impact on heat transfer coefficients $[19,20]$. It has been noted that the SJ heat transfer characteristics depend on the dimensionless stroke length, which is the parameter that nondimensionalizes the frequency. Thus, knowledge about resonance frequencies, including the Helmholtz resonant frequency, can also be of significance in SJ heat transfer issues.

The main goal of the present research was to determine the mathematical formula of a model to calculate the Helmholtz resonance frequency in the case of synthetic jet actuators.

A problem associated with analytical modeling of SJ actuator characteristics was raised by Gallas et al. [14-16]. In this study, the researchers proposed a lumped element model based on an analogy with electrical circuitry. In this model, the components of a piezoelectrically driven SJ actuator were modeled as analogous actuators of an electrical circuit. The modification of the lumped element model was proposed by Thang and Zhong [21]. In their model, the mechanical movement of the diaphragm was decoupled from the fluid phenomenon in the cavity, which allowed the modeling of the SJ actuator to be separately investigated and validated. A general lumped parameter model for an SJ actuator with an electromagnetic or piezoelectric driver was presented by Persoons [22]. This article includes a detailed description of the coupling between the electromechanical driver model and fluidic effects in the cavity. The author experimentally validated the model for circular and rectangular orifices. A lumped element model of the operation of an SJ actuator driven by a thin piezoelectric disk was also studied by de Luca et al. [23]. The authors reported the results of analytical and numerical investigations performed to obtain the information about the frequency response of the studied device. Furthermore, Gomes et al. [24] studied the influence of the geometry, such as the cavity height and the orifice length, on the synthetic jet velocity derived from the piezo SJ actuator and, consequently, the SJA Helmholtz resonance frequencies. The application of lumped element models to SJs, also referred to as reduced-order models, was also presented and discussed in $[13,25,26]$. In addition, based on lumped element modeling and the assumption of an incompressible working fluid, Kordik and Travnicek [13] theoretically predicted the optimal diameters of SJ actuator orifices in the cases investigated. A previous study [25] includes a comprehensive review of the development of various lumped element models as practical tools to design and manufacture SJ actuators. The authors of [26] present a reduced-order model that was developed to predict the performance of synthetic jet actuators. The research concerned a classical SJA configuration consisting of a single actuator with rectangular orifice. The CFD results from both 2D and 3D simulations were compared. The authors also compared their numerical results with the experiment, and drew conclusions regarding the validity of the relatively simple analytical method for a variety of conditions, and for a range of frequencies approaching the Helmholtz resonance frequency.

An alternative analytical model of the SJ actuator has been presented by Sharma $[17,18]$. In the proposed model, the driven wall in the cavity is a mechanical system which is pneumatically coupled to the cavity-orifice system operating as a Helmholtz resonator. It should be noted that most of the works cited above concern the use of piezo-driven SJ actuators.

The validation of the findings obtained above appears to be justified for loudspeaker SJ actuators, and was one of the objectives of the present work. The SJA Helmholtz resonance 
frequency is the subject of the present study. Experimental investigations of 108 various geometrical configurations of a synthetic jet actuator were undertaken to determine the impact of the geometry on the Helmholtz resonance frequency. Orifice diameter, orifice length, and cavity volume were changed within a wide range. The existing model used to describe the Helmholtz resonance frequency in the SJ system was verified and calibrated.

\section{Materials and Methods}

The experiment was performed using a modular synthetic jet actuator that enabled rapid changes in its geometry. The scheme of the applied SJ actuator is presented in Figure 1.

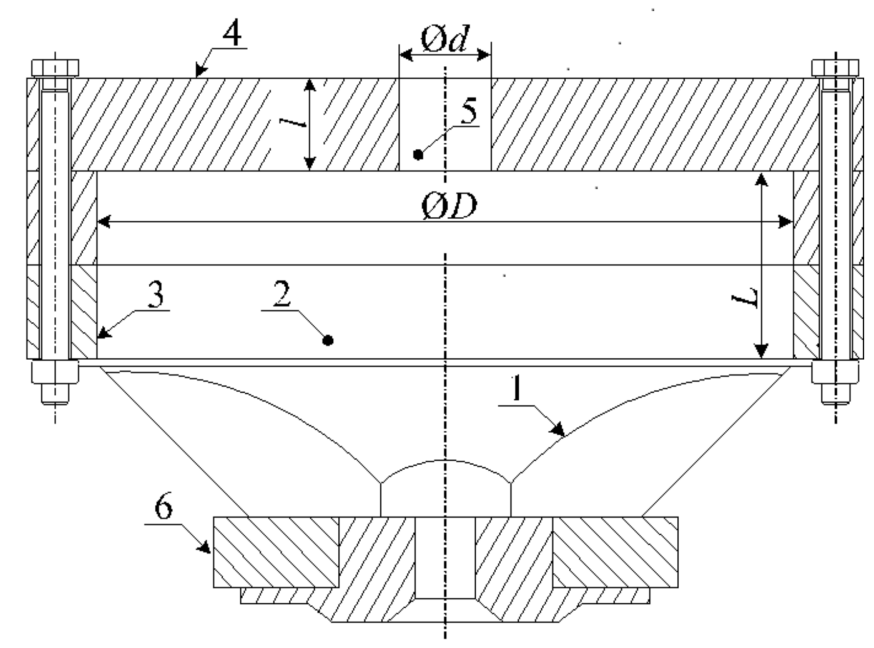

Figure 1. Schematic diagram of the investigated synthetic jet actuator: 1-diaphragm, 2-cavity, 3-spacer plate, 4-front plate with orifice, 5-orifice, 6-loudspeaker.

The actuator consisted of a plexiglass cavity and loudspeaker. Plexiglass spacer plates forming the cavity could be set up quickly and easily. Changing the configuration of the plates resulted in different cavity volumes, in addition to different diameters and lengths of the orifice. Views of the modular SJ actuator in the case of maximum and minimum cavity volume are shown Figure 2. Figure 3 presents the general scheme of the measurement system applied in the investigations.

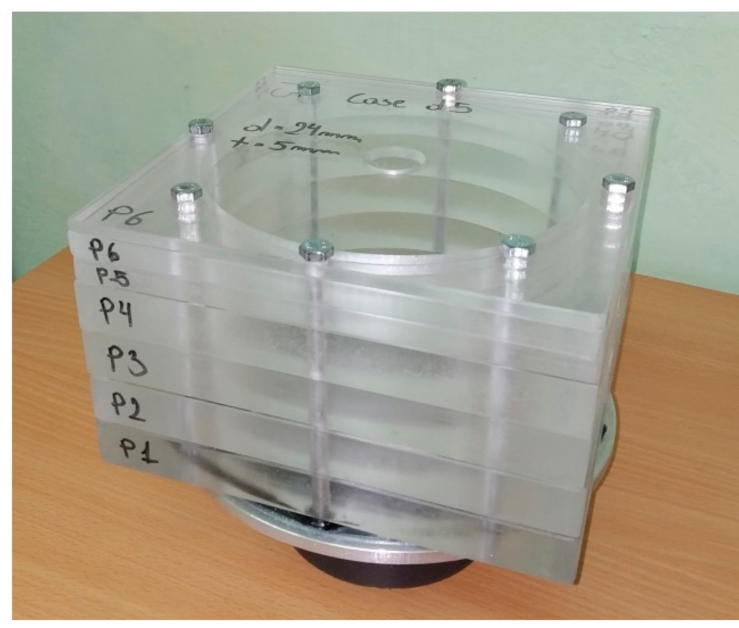

(a)

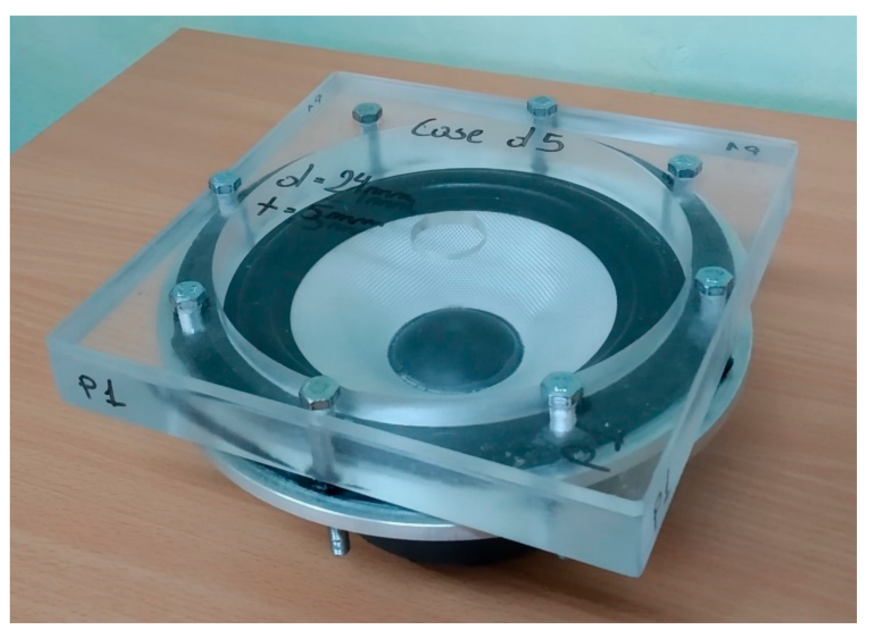

(b)

Figure 2. Modular SJ actuator: (a) maximum volume of the cavity; (b) minimum volume of the cavity. 


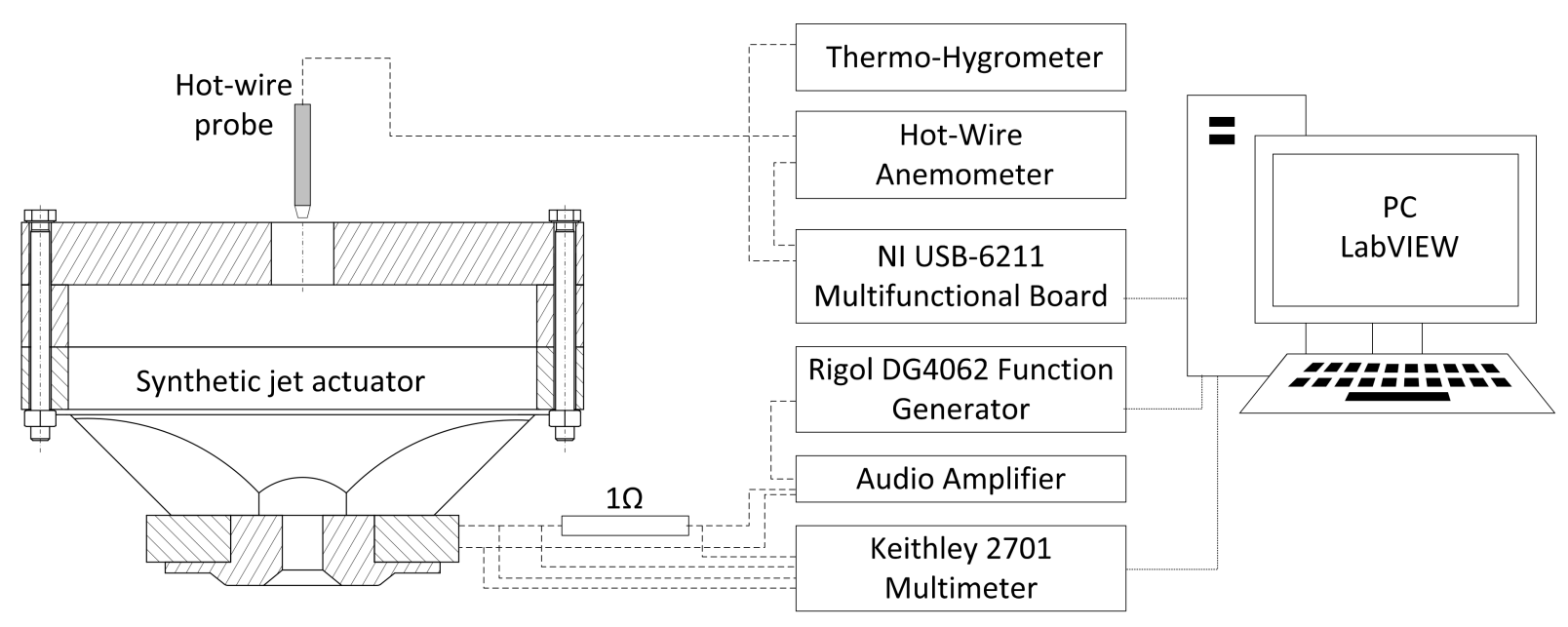

Figure 3. Scheme of the measurement system.

The dimensions of the square distance plates were: thickness of 10 or $20 \mathrm{~mm}$; side length of $180 \mathrm{~mm}$. The volume of the cavity was set by increasing the number of plates between the loudspeaker and the front plate with the orifice (see Figure 1). Each distance plate had a circular hole with diameter of about $D=150 \mathrm{~mm}$. A detailed description of the parameters that characterized the cavity formed by the distance plates is included in Table 1. The dimensions of a single distance plate were based on direct measurement. By increasing the cavity volume $V$, the diameter $D$ was determined as the weighted average of the hole diameters of the component plates. The cavity volume $V$ was the sum of the space resulting from the distance plates and the volume of the loudspeaker diaphragm cavity.

Table 1. Parameters of the cavity used in the SJ actuator investigations.

\begin{tabular}{ccccc}
\hline Case & $\begin{array}{c}\text { Cavity } \\
\text { Length, } \\
\boldsymbol{L}[\mathbf{m m}]\end{array}$ & $\begin{array}{c}\text { Cavity } \\
\text { Internal } \\
\text { Diameter, } \\
\boldsymbol{D}[\mathbf{m m}]\end{array}$ & $\begin{array}{c}\text { Cavity } \\
\text { Volume, } \\
\boldsymbol{V}\left[\mathbf{c m}^{\mathbf{3}}\right]\end{array}$ & $\mathbf{L} \boldsymbol{D}[-]$ \\
\hline V-1 & 19.97 & 149.84 & 489.3 & 0.13 \\
V-2 & 29.42 & 149.83 & 655.9 & 0.20 \\
V-3 & 39.95 & 149.89 & 842.0 & 0.27 \\
V-4 & 49.40 & 149.87 & 1009.0 & 0.33 \\
V-5 & 59.82 & 149.80 & 1191.0 & 0.40 \\
V-6 & 69.27 & 149.80 & 1358.0 & 0.46 \\
V-7 & 79.72 & 149.80 & 1542.0 & 0.53 \\
V-8 & 89.17 & 149.80 & 1709.0 & 0.60 \\
V-9 & 98.60 & 149.81 & 1875.0 & 0.66 \\
\hline
\end{tabular}

The front plate was able to be replaced in the 12 available cases. Table 2 presents a detailed description of the parameters that characterized the front plates with orifices. Geometrical measurements were made using an InSize150 electronic caliper with an accuracy of $\pm 0.01 \mathrm{~mm}$. Ten measurements were made for each dimension; the final result was the average of the measurements taken.

An STX W.18.200.8.FGX-type loudspeaker was used in the investigations, and is characterized by a nominal resonance frequency of $37 \mathrm{~Hz}$ and nominal impedance of $8 \Omega$. An analog sinusoidal signal was generated by a RIGOL DG4062 function generator and amplified by an AUNA CD-708 acoustic amplifier. Measurements of the effective voltage, current, and frequency of the supply signal were made using a Keithley 2700 multimeter with a 7702 plug-in card. For electric current measurement, a precision current shunt with an accuracy of $\pm 0.01 \%$ was used, the voltage drop of which was measured by a Keithley multimeter. The accuracy of voltage and effective current measurements was better than 
$\pm 0.2 \%$ of the measured value. The measurement accuracy of the frequency was better than $\pm 0.05 \%$ of the measured value.

Table 2. Dimensions of the available front plates with orifices.

\begin{tabular}{cccc}
\hline Case & $\begin{array}{c}\text { Orifice } \\
\text { Diameter, } \\
\boldsymbol{d}[\mathbf{m m}]\end{array}$ & $\begin{array}{c}\text { Orifice } \\
\text { Length, } \\
\boldsymbol{l}[\mathbf{m m}]\end{array}$ & $\boldsymbol{l} / \boldsymbol{d}[-]$ \\
\hline dl-1 & 6.20 & 4.78 & 0.77 \\
dl-2 & 9.12 & 4.81 & 0.53 \\
dl-3 & 15.03 & 4.84 & 0.32 \\
dl-4 & 19.95 & 4.80 & 0.24 \\
dl-5 & 23.95 & 4.79 & 0.20 \\
dl-6 & 30.01 & 4.79 & 0.16 \\
dl-7 & 19.99 & 9.47 & 0.47 \\
dl-8 & 19.97 & 14.27 & 0.71 \\
dl-9 & 19.97 & 19.80 & 0.99 \\
dl-10 & 19.98 & 29.27 & 1.46 \\
dl-11 & 19.99 & 39.78 & 1.99 \\
dl-12 & 19.99 & 59.83 & 2.99 \\
\hline
\end{tabular}

A constant temperature hot-wire HPA 98 anemometer having a calibrated single wire probe with a sensing element length of about $2 \mathrm{~mm}$ and a diameter of $5 \mu \mathrm{m}$ was used for the velocity measurements. Calibration of the anemometer was performed in the velocity range from 0.2 to about $30 \mathrm{~m} / \mathrm{s}$. The voltage signal from the anemometer was recorded by an NI USB 6211 measurement card. The probe was placed in the orifice axis and in the orifice outlet plane. The velocity measurement accuracy was described in detail in reference [3].

During all measurements, the laboratory room was air conditioned, and constant temperature and relative humidity were maintained in the ranges of $21 \pm 1{ }^{\circ} \mathrm{C}$ and $35 \% \pm 5 \%$, respectively. The ambient pressure fluctuated within the range 99,200 $\pm 500 \mathrm{~Pa}$. Temperature and humidity measurements were taken using a APAR AR252 thermo hygrometer with an accuracy of $\pm 0.3{ }^{\circ} \mathrm{C}$ and $\pm 2 \%$, respectively. The ambient pressure measurement was carried out using a Honeywell HPB200W2DA-B barometer with an accuracy of $\pm 40 \mathrm{~Pa}$.

The conducted experimental investigations included $108(9 \times 12)$ cases, which were a combination of the cavity volume from Table 1 and the front plate with orifices from Table 2. The symbols used in the description of the results (Section 3 ) indicate, for example: Case dl-4/V-2 represents the connection of the front plate $\mathrm{dl}-4(d=19.95 \mathrm{~mm} ; l=4.80 \mathrm{~mm})$ with the distance plates of total thickness (length) $L=29.42 \mathrm{~mm}$ and total cavity volume $V=655.9 \mathrm{~cm}^{3}(\mathrm{~V}-2)$.

Measurements were carried for excitation frequencies within a range of $f=10-700 \mathrm{~Hz}$ for each of the considered SJ actuator geometries. In the first step, the excitation frequency was measured at intervals of $10 \mathrm{~Hz}$. Then, the local maxima were searched for. The second measurement was made around the initially obtained maximum, at a measurement resolution of $1 \mathrm{~Hz}$. This measurement procedure significantly reduced the measurement time while ensuring high measurement resolution.

\section{Results}

\subsection{Identification of Resonance Frequencies}

The resonance frequencies of the SJ actuator were identified from the measurement of the electric apparent power with the constant voltage $E$ operation. The apparent power $P$ supplied by the actuator is a product of the measured effective voltage $E$ value and the effective electric current $I$.

Figure 4 presents the characteristic of the apparent power consumed by the actuator when supplied with an effective voltage of $3 \mathrm{~V}$ in the case of $\mathrm{SJ}$ actuator geometries dl-9/V1dl-9/V9. It can be seen that two local minima of the power occur. These characteristic 
points correspond to the two resonance frequencies. The first power minimum occurs at the diaphragm resonance frequency equal to $f_{D}=19 \mathrm{~Hz}$. This frequency depends on the loudspeaker parameters and the vibrating air mass in the volume of the orifice [13]. The second observed resonance frequency observed is the Helmholtz resonance frequency. In the case of $\mathrm{SJ}$ actuator geometry dl-9/V1, the Helmholtz resonance frequency is equal to $f_{H}=352 \mathrm{~Hz}$. As the cavity volume increases, the value of $f_{H}$ decreases, and reaches a value equal to $184 \mathrm{~Hz}$ for the case of dl-9/V9.

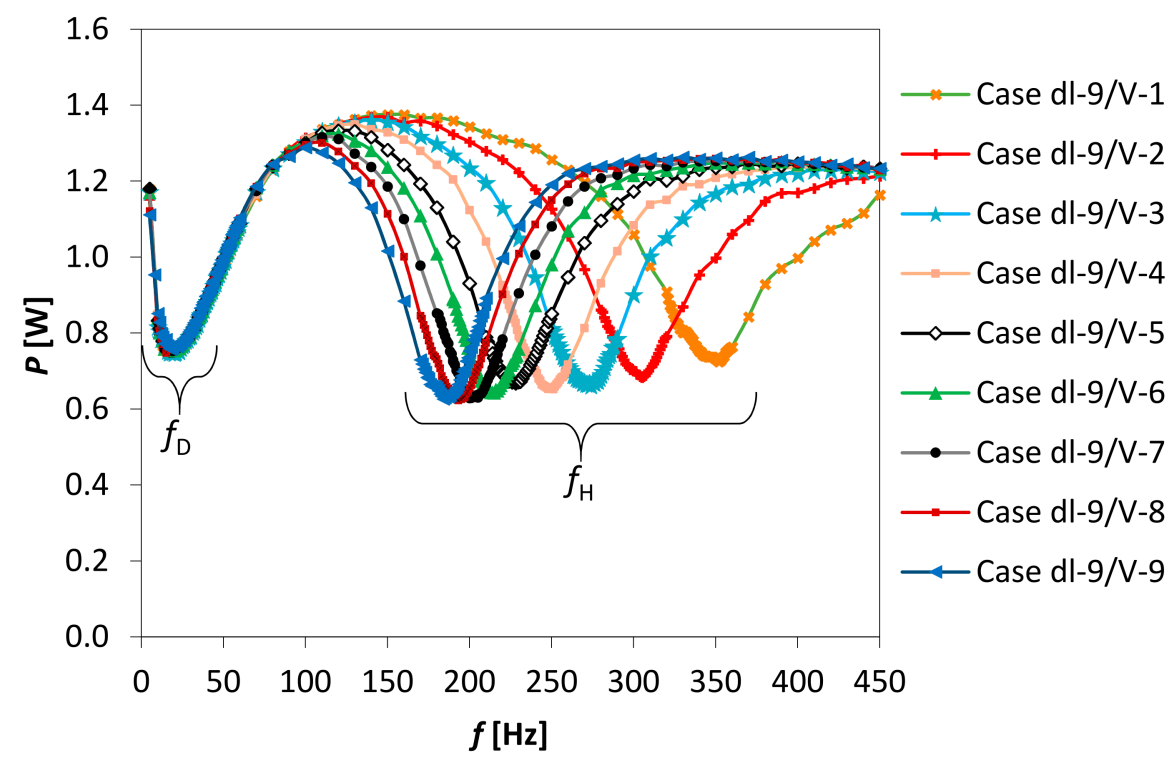

Figure 4. Dependence of SJA apparent power on excitation frequency for effective voltage $E=3 \mathrm{~V}$.

Resonance frequencies were also determined from the frequency-impedance characteristic. The impedance $Z$ is the ratio of effective voltage $E$ divided by the effective electric current $I$ feeding the SJA. Because both impedance and apparent power are directly dependent only on the effective electric current and effective voltage, the resonance frequency will be the same for both characteristics. In the case of the impedance characteristics, the local maxima occur at the diaphragm resonance frequency and at the Helmholtz resonance frequency.

Determination of the resonance frequencies is also possible on the basis of velocity measurements. The centerline momentum velocity $U$ in the orifice exit plane was obtained from the formula:

$$
U=\sqrt{\frac{1}{T} \int_{0}^{T}\left(u^{2}\right) d \tau},
$$

where $T$ is an oscillation period and $u$ is an instantaneous velocity.

The dependence of $U$ on $f$ is presented in Figure 5. Maxima of the characteristic velocity occur at the resonance frequencies. The estimation of resonance frequencies from the characteristic velocity was utilized in the reference [11,12]. This measurement technique has lower precision and results in more scattered data than the impedance measurement technique. In addition, the hot-wire measurement required calibration, room temperature stabilization, and temperature compensation, in addition to precise positioning of the probe. 


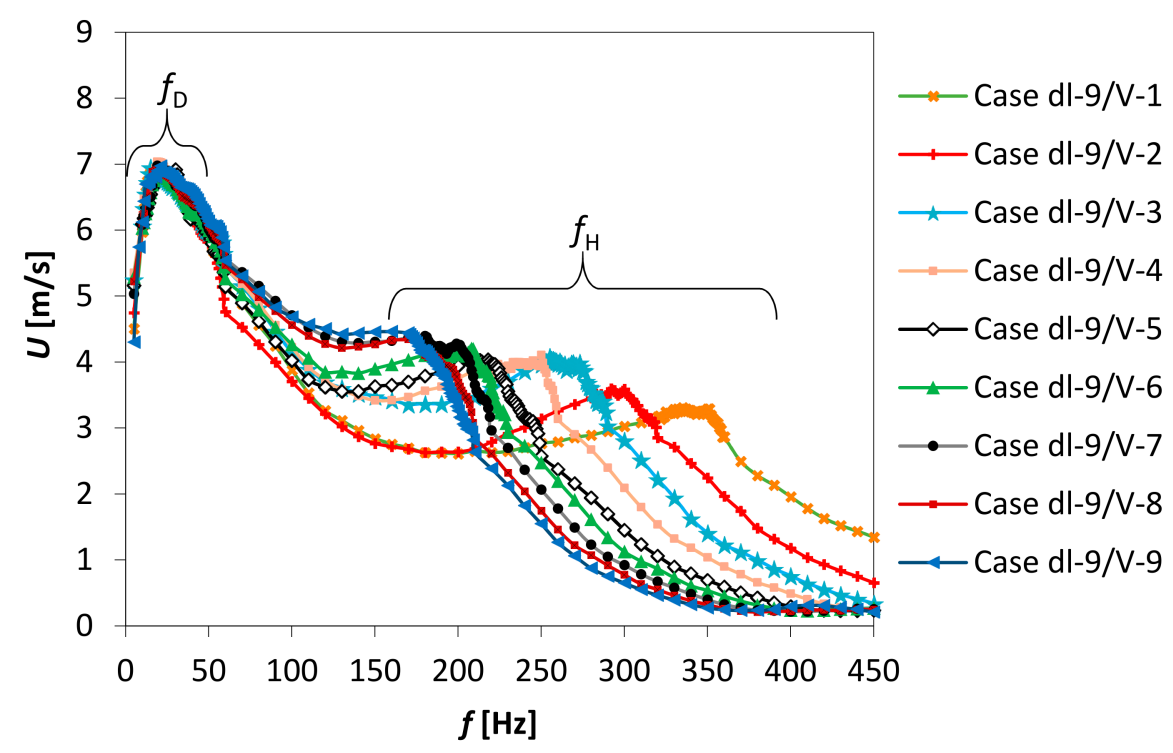

Figure 5. Synthetic jet momentum velocity as a function of excitation frequency for $E=3 \mathrm{~V}$ for various cavity depth.

The comparison of the Helmholtz resonance frequencies obtained from impedance measurement $f_{H}(Z)$ and momentum velocity measurement $f_{H}(U)$ is presented in Figure 6, which shows a high compliance of the results.

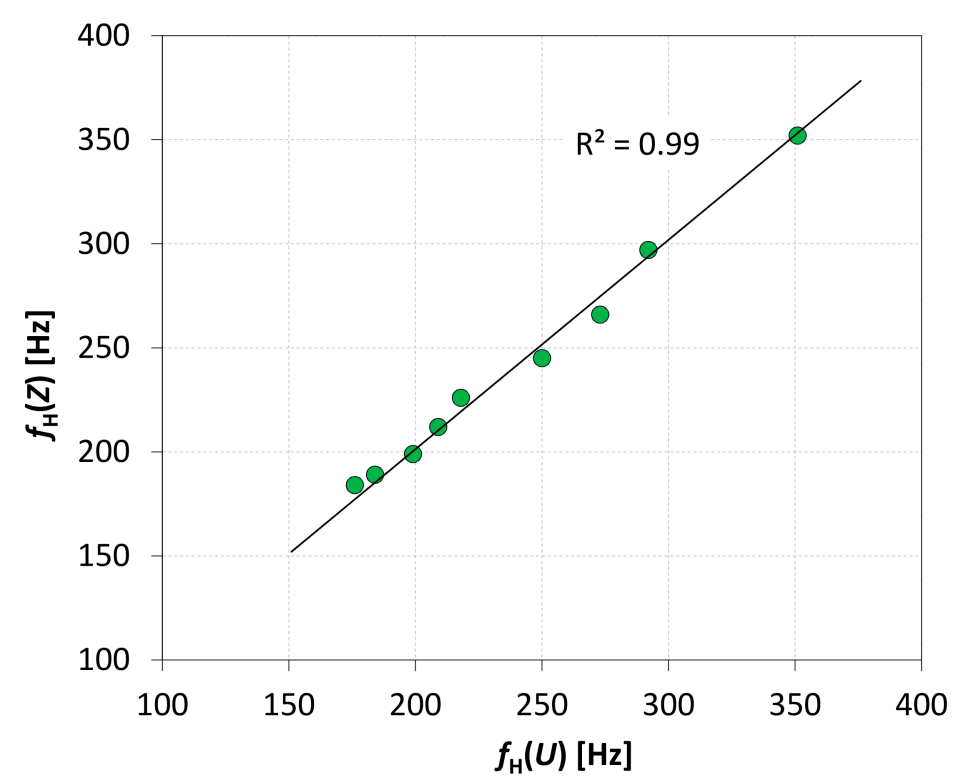

Figure 6. Comparison of Helmholtz resonance frequencies received from various measurement techniques.

As discussed previously, the Helmholtz resonance frequency can be determined from measurements of electrical parameters or measurements of the air velocity. Due to the better precision and repeatability of the electrical measurements in relation to the air velocity measurements with the use of constant temperature anemometry, Helmholtz resonance frequencies necessary for the validation of the mathematical model were determined from impedance measurements.

\subsection{Effects of The Supply Voltage and SJ Actuator Geometrical Parameters on the Helmholtz Resonance Frequency}

To select the effective voltage used to supply the synthetic jet actuator, an experiment was carried out to determine the impedance characteristics. These were functions of the 
frequency for the same geometry of the actuator. The effective voltage was changed from 0.2 to $3 \mathrm{~V}$. Figure 7 presents results of the experiment in the case of dl-9/V8 actuator geometry. Similar to the case of the previous investigations, two resonance frequencies are observed: the first diaphragm frequency of $f_{D}=19 \mathrm{~Hz}$, and the second, the Helmholtz resonance frequency of $f_{H}=183 \mathrm{~Hz}$. The impedance changes with the increase in effective voltage. However, the frequency of the resonance occurrence remains the same within tolerance of $\pm 1 \mathrm{~Hz}$. Thus, it can be concluded that the resonance frequencies do not depend on the actuator supply voltage in the considered range of effective voltages.

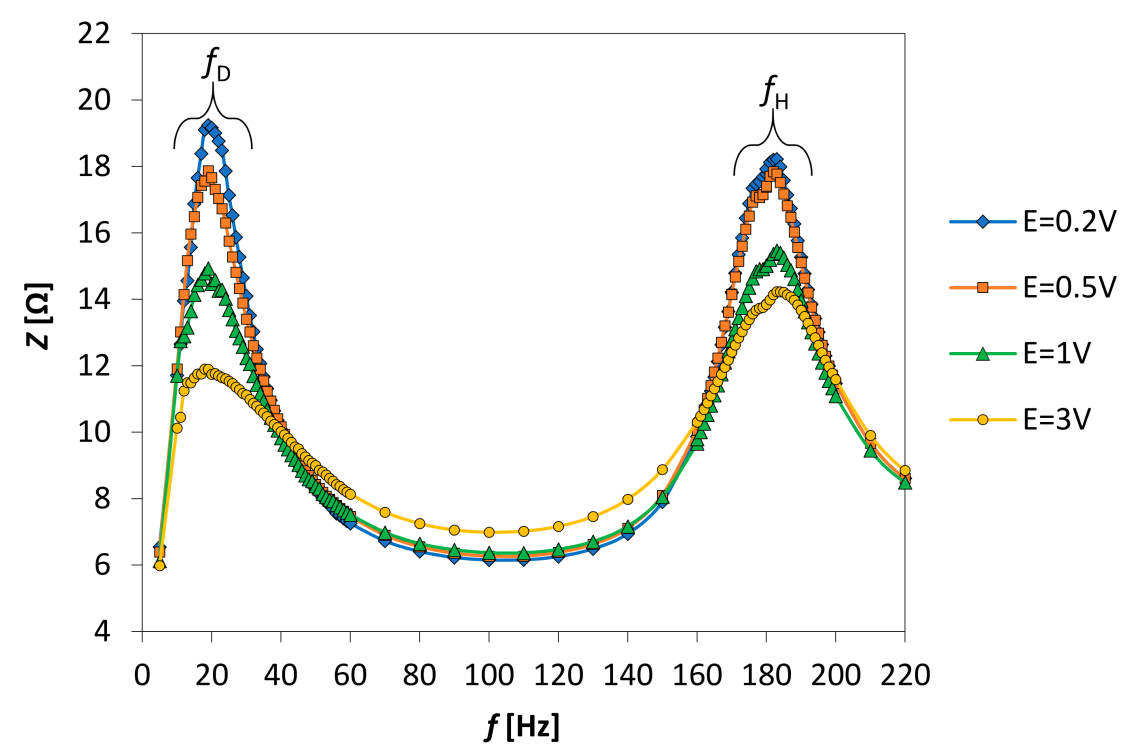

Figure 7. Effect of SJA supply voltage on the frequency of resonances.

The next step was to determine the influence of the basic SJ actuator geometrical parameters on the value of the Helmholtz resonance frequency. Investigations were performed by changing the orifice diameter $d$, orifice length $l$, and cavity volume $V$. The results are shown in Figures 8 and 9.

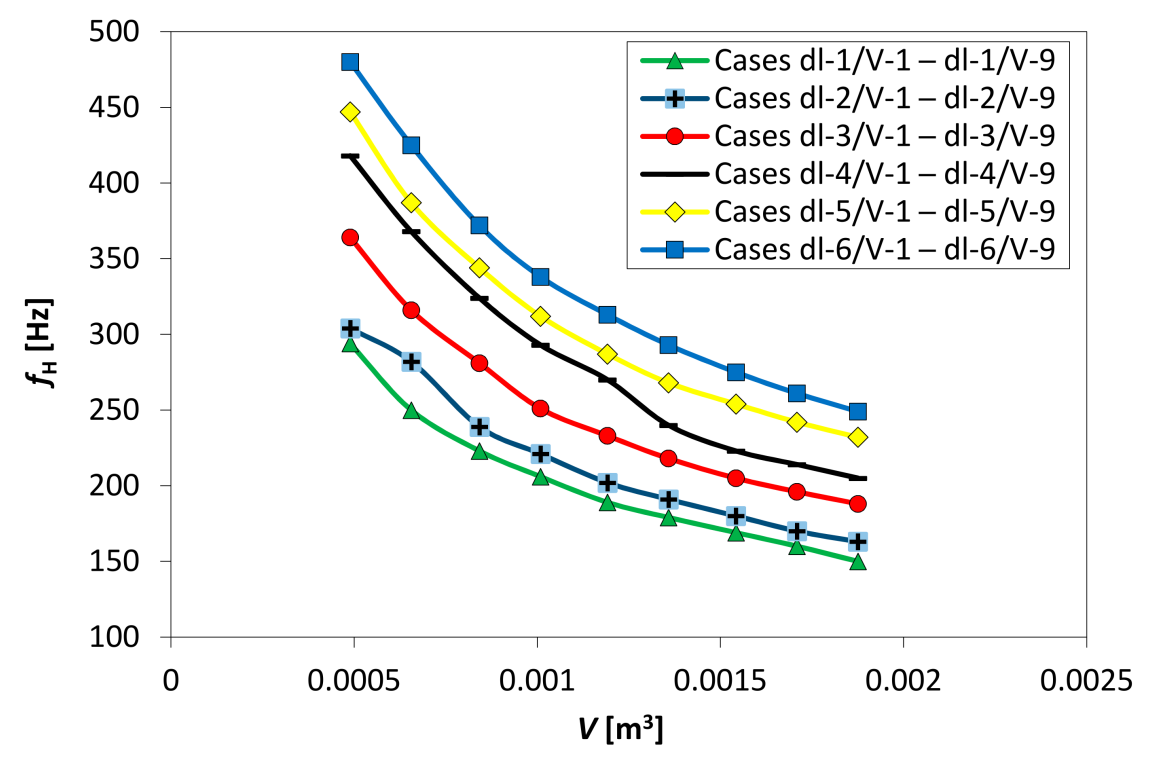

Figure 8. Effect of cavity volume and orifice diameter on the Helmholtz resonance frequency-the case of constant orifice length. 


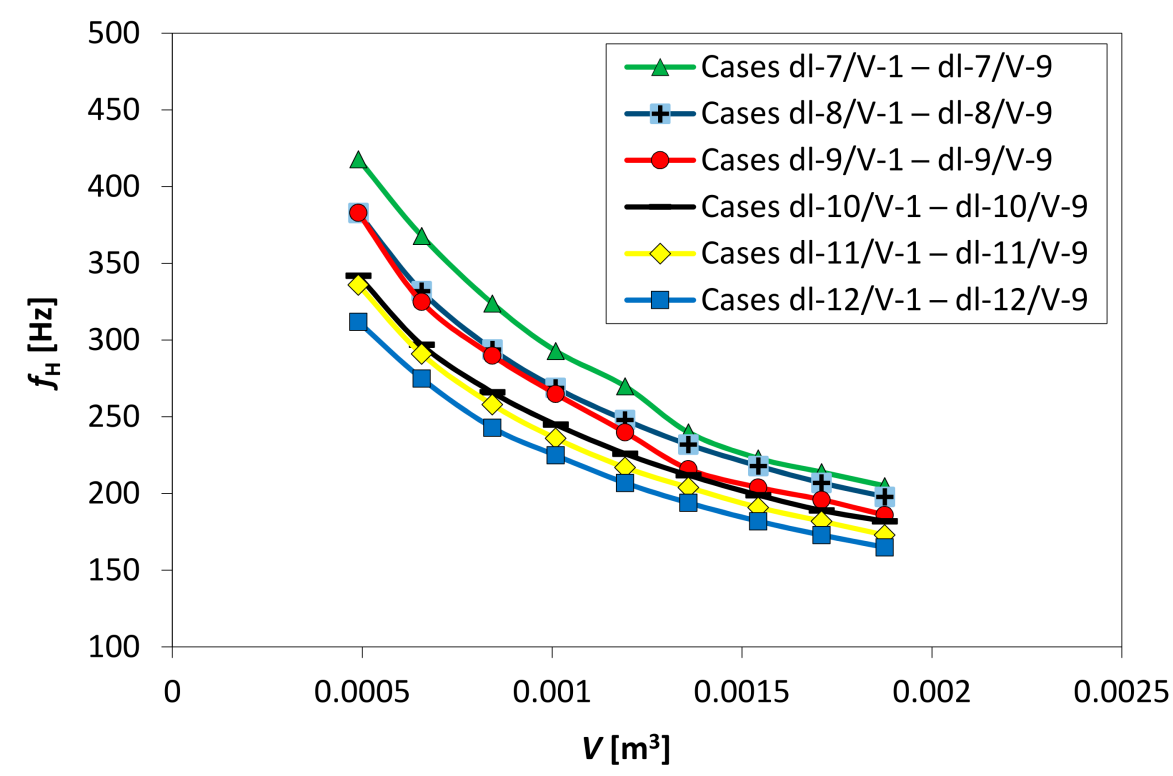

Figure 9. Effect of cavity volume and orifice length on the Helmholtz resonance frequency-the case of constant orifice diameter.

The results show a decrease in $f_{H}$ with an increase in $V$, both in the case of constant $d$ or $l$ values. In turn, Helmholtz resonance frequency increases as the orifice diameter increases at a constant value of the cavity volume and decreases as the orifice length increases.

\section{Discussion}

\subsection{Helmholtz Resonance Frequency Model}

The Helmholtz resonance frequency is usually recognized to be [23]:

$$
f_{\mathrm{H}}=\frac{1}{2 \pi} \cdot \sqrt{\frac{\kappa \cdot A^{2} \cdot p_{a}}{m \cdot V}}
$$

where: $\kappa$ —specific heat ratio, $A$ —orifice surface area, $p_{a}$ —ambient pressure and:

$$
m=\rho \cdot A \cdot l_{e}
$$

where $l_{e}$ represents the effective orifice length.

In turn, assuming that air is an ideal gas, the isentropic speed of sound is given by:

$$
v=\sqrt{\frac{\kappa \cdot p_{a}}{\rho}}
$$

where $\rho$ is air density.

Considering the above, it can be written that:

$$
f_{\mathrm{H}}=\frac{v}{2 \pi} \cdot \sqrt{\frac{A}{V \cdot l_{e}}}
$$

The effective (modified) length of the orifice $l_{e}$ resulting from the application of the Bernoulli equation in the modeling of synthetic jet actuation [18] is evaluated according to:

$$
l_{\mathrm{e}}=l+\Delta l
$$

Typically, the additive length $\Delta l$ can be adopted [23]:

$$
\Delta l=0.62 \cdot d
$$


Values of the constant factor greater than 0.62 in the above equation have also been used in some considerations. For example, in acoustics investigations it is equal to 0.8 [27].

The Helmholtz resonance frequency is also obtained basing on the lumped element model of a synthetic jet actuator. In this case, the components of a synthetic jet actuator are modeled as elements of an analogous electrical circuit. According to the model [15], Helmholtz resonance frequency is given by:

$$
f_{\mathrm{H}}=\frac{1}{2 \pi} \cdot\left[\left(M_{\mathrm{aN}}+M_{\mathrm{arad}}\right)\left(C_{\mathrm{aC}}\right)\right]^{-0.5}
$$

where: $M_{\mathrm{aN}}$ and $M_{\mathrm{arad}}$ are the effective acoustic mass and the acoustic radiation mass, respectively; $C_{\mathrm{aC}}$ is the acoustic compliance of the cavity. Assuming that air is an ideal gas, the acoustic cavity compliance is given by [15]:

$$
C_{\mathrm{aC}}=\frac{V}{\rho \cdot v^{2}}
$$

Taking into account Equation (9) and the model proposed in [15], which allows $M_{\mathrm{aN}}$ and $M_{\text {arad }}$ to be determined, Equation (8) takes the form:

$$
f_{\mathrm{H}}=\frac{1}{2 \pi} \cdot\left[\left(\left(\frac{16 \cdot \rho \cdot l}{3 \cdot \pi \cdot d^{2}}\right)+\left(\frac{16 \cdot \rho}{3 \cdot \pi^{2} \cdot d}\right)\right)\left(\frac{V}{\rho \cdot v^{2}}\right)\right]^{-0,5}
$$

After transformations, taking into account that orifice area $A=\pi \cdot d^{2} / 4$, Equation (10) can be written as:

$$
f_{\mathrm{H}}=\frac{v}{2 \pi} \cdot \sqrt{\frac{A}{V \cdot\left(l+\frac{l}{3}+\frac{4 \cdot d}{3 \cdot \pi}\right)}}=\frac{v}{2 \pi} \cdot \sqrt{\frac{A}{V \cdot l_{e}}}
$$

where:

$$
l_{\mathrm{e}}=l+\Delta l=l+\left(\frac{l}{3}+\frac{4 \cdot d}{3 \cdot \pi}\right)
$$

which is equivalent to:

$$
\frac{\Delta l}{d}=\left(\frac{l}{3 \cdot d}+\frac{4}{3 \cdot \pi}\right)=f\left(\frac{l}{d}\right)
$$

As can be seen, the term $\Delta l / d$ is a function of the ratio of the orifice length to the orifice diameter, in contrast to the classical case, in which this term has a constant value (Equation (7)).

\subsection{The Improved Version of the Model}

Based on the above formulas, Table 3 summarizes the cases of the mathematical model describing the Helmholtz resonance frequency, taking into account the effective orifice length.

Table 3. $\Delta l / d$ ratio in the Helmholtz resonance frequency model.

\begin{tabular}{cc}
\hline Model & $\Delta l / d$ \\
\hline M1 & 0.62 \\
M1 & 0.8 \\
M2 & $l /(3 d)+4 /(3 \pi)$ \\
\hline
\end{tabular}

The SJA Helmholtz resonance frequency determined from experiments was compared with mathematical models: Equations (5) and (11). The comparison is presented in Figure 10. The figure shows that all models significantly underestimate the Helmholtz resonance frequency. The average relative error is approximately $50 \%$. 


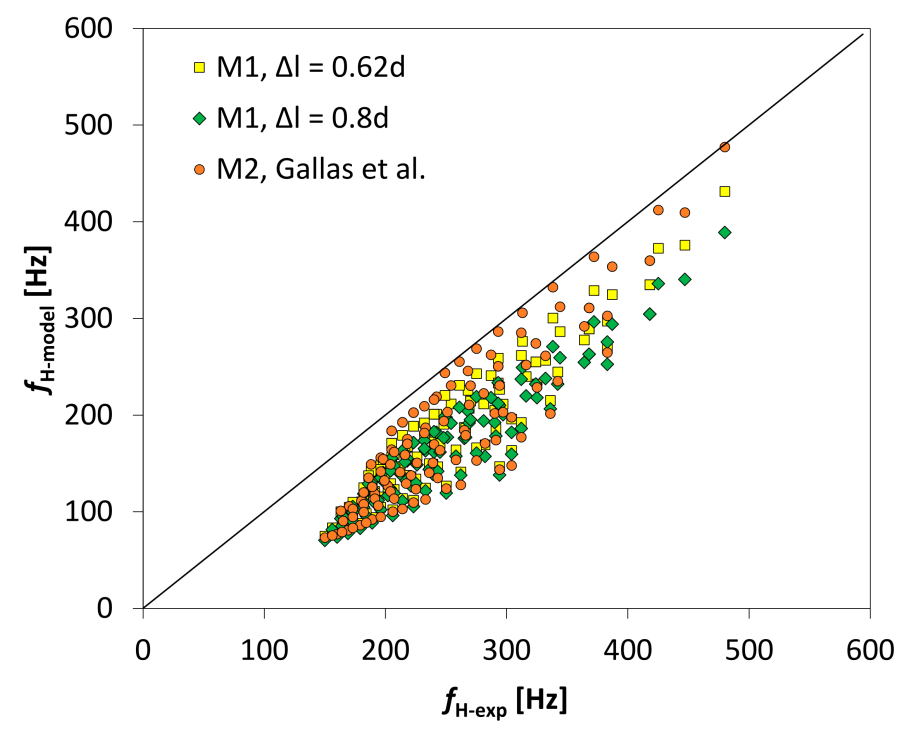

Figure 10. The comparison of Helmholtz resonance frequencies obtained from experiments and models: Equations (5) and (11).

Taking into account the impact of the SJ actuator geometry on the effective orifice length $l_{e}$ in the model M2, the experimental results were compared with those obtained from the M2 model. Figure 11 presents the first comparison as a ratio of the frequencies modeled by the M2 model to the Helmholtz resonance frequencies obtained from the experimental value of $f_{\mathrm{H}-\mathrm{M} 2} / f_{\mathrm{H}-\exp }$ as a function of the $l / d$ ratio. All tested cases were included. As can be seen, the convergence of the model with the experimental values decreases with the increase in the $l / d$ ratio.

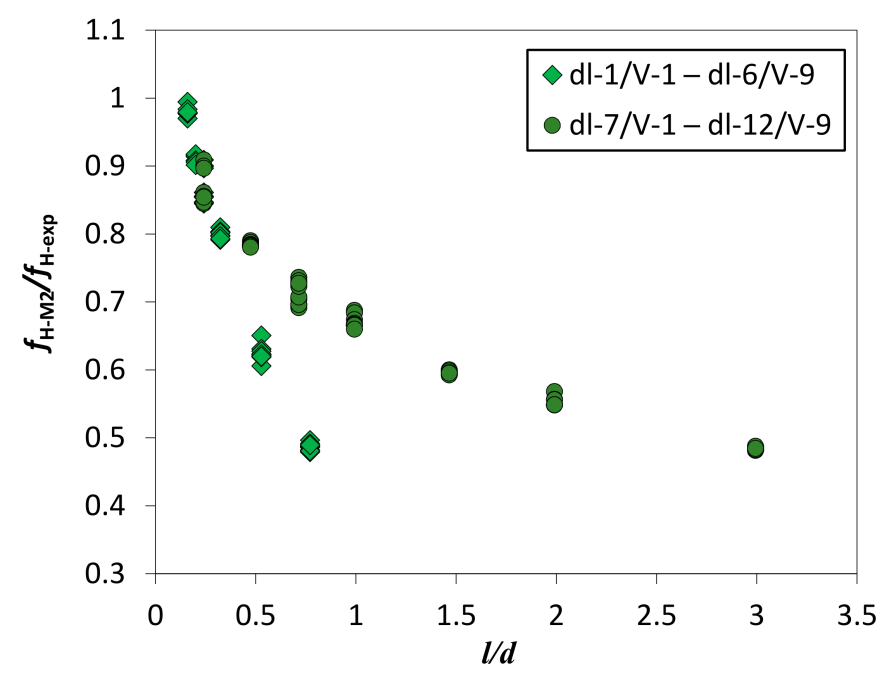

Figure 11. The ratio of frequencies obtained from the M2 model to the experimental results as a function of $l / d$.

To merge the data series from Figure 11, an additional dimensionless variablesurfaces ratio $\sigma$-was introduced:

$$
\sigma=\frac{\frac{\pi}{4} d^{2}}{\frac{\pi}{4} D^{2}}=\frac{d^{2}}{D^{2}}
$$

Figure 12 presents the second comparison of the $f_{\mathrm{H}-\mathrm{M} 2} / f_{\mathrm{H}-\exp }$ ratio as a function of $\sigma$ at a constant value of the orifice length. This applies to the $\mathrm{SJ}$ actuator geometries from dl$1 / \mathrm{V}-1$ - dl-1/V-9 to dl-6/V-1—dl-6/V-9 (54 cases). As can be seen, $f_{\mathrm{H}-\mathrm{M} 2} / f_{\mathrm{H}-\exp }$ increases 
with the increase in the ratio of the orifice cross-sectional area to the cross-sectional area of the cavity. The theoretical model and the experiment converge at $\sigma=0.04$.

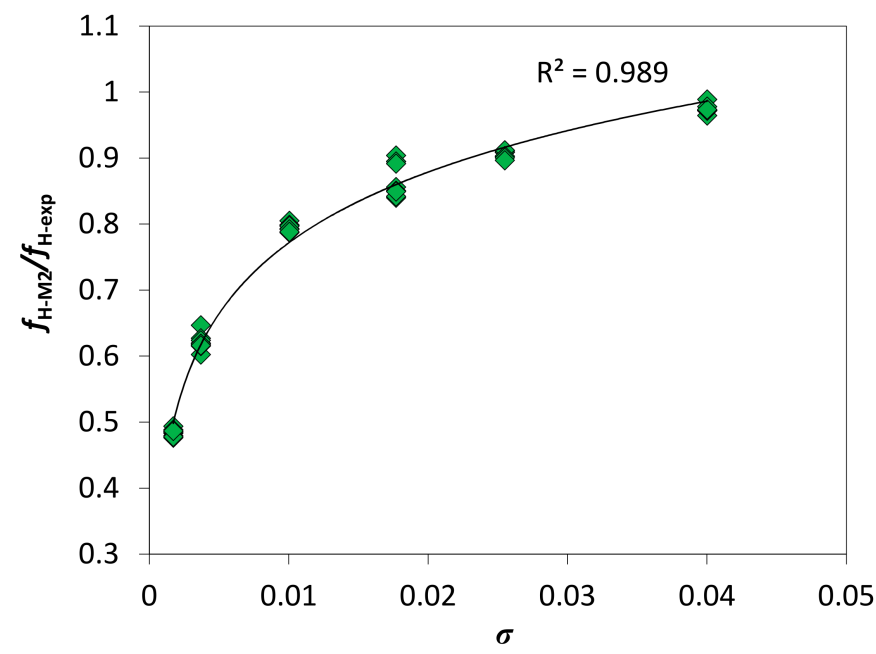

Figure 12. The $f_{\mathrm{H}-\mathrm{M} 2} / f_{\mathrm{H}-\exp }$ ratio as a function of parameter $\sigma(\mathrm{dl}-7 / \mathrm{V}-1-\mathrm{dl}-12 / \mathrm{V}-9)$.

The above discussion shows that the compliance of the model M2 with the obtained experimental results was achieved for a small range of the cases considered. Using the regression method, the analytical relationship between the effective orifice length and the geometrical parameters $l / d$ and $\sigma$ was obtained for the range of the cases investigated. This is given by:

$$
\frac{l_{e}}{d}=\sigma^{0.25}\left(1.367+0.5173 \frac{l}{d}\right)
$$

In this manner, the M3 model was created. Thus, Table 3 may be supplemented with the M3 model, where the $\Delta l / d$ ratio is given by:

$$
\frac{\Delta l}{d}=\sigma^{0.25}\left(1.367+0.5173 \frac{l}{d}\right)-\frac{l}{d}
$$

The comparison of the Helmholtz resonance frequency obtained from the experiment with that calculated from the M3 model is shown in Figure 13. Of the results from the M3 model, $95 \%$ are in the range of $\pm 6 \%$ relative to the experiment.

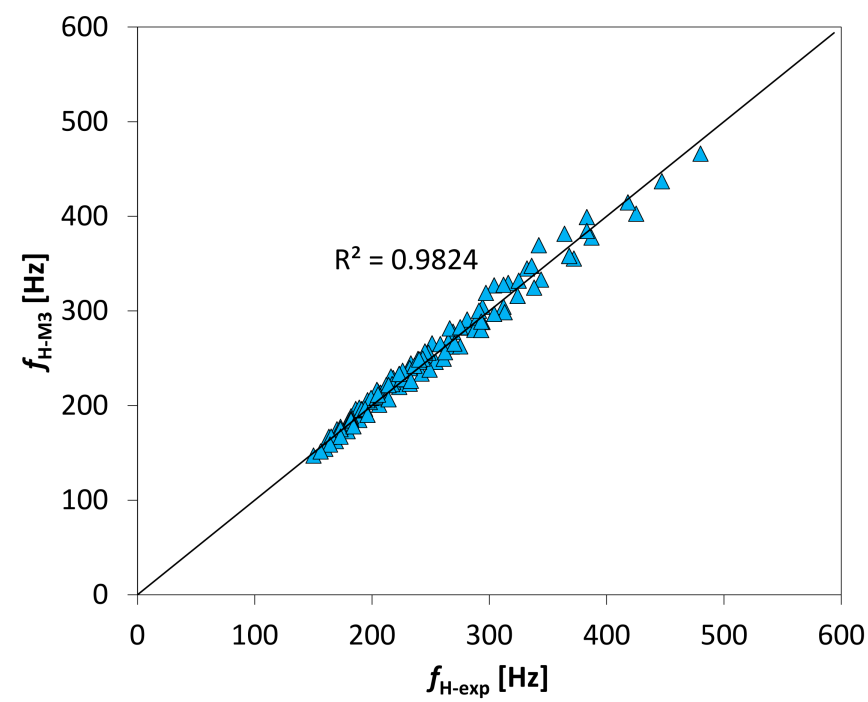

Figure 13. Results of the Helmholtz resonance frequency obtained from the M3 model and the experiment. 
A spatial graph showing the dependence of the dimensionless effective orifice length on the geometrical parameters $l / d$ and $\sigma$ is presented in Figure 14. As can be seen, $l_{e}$ is strongly related to the ratio of the orifice area to the cavity cross-sectional area.

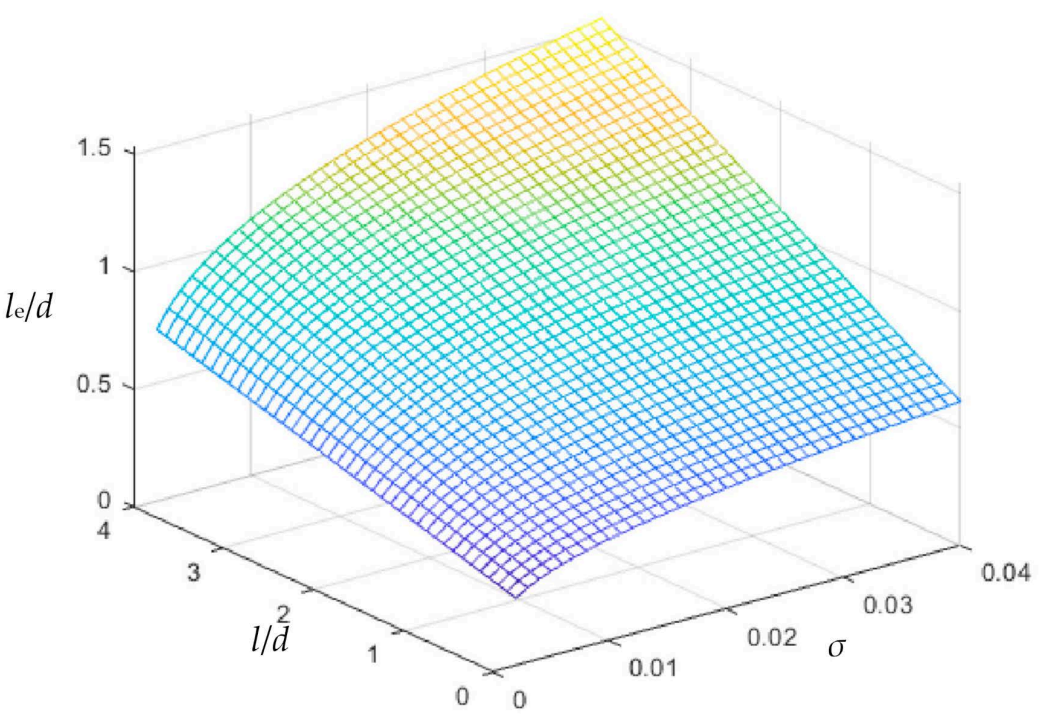

Figure 14. Dimensionless effective orifice length as a function of the ratio of the orifice area to the cavity cross-section area, and the dimensionless orifice length.

It should be noted that the $\sigma$ parameter appears in the analytical model for SJ actuation based on the fluid dynamics laws, as presented by Sharma [18]. Analyzing the unsteady Bernoulli equation, the author presents the dependence of the orifice loss coefficient on $\sigma$. The present experimental research indicates that the effective orifice length/effective length of the air $l_{e}$ represented by the inertia coefficient [18] is also a function of the $\sigma$ parameter.

Considering the base Equation (5), which presents the Helmholtz resonance frequency, and taking into account that:

$$
\frac{A}{V}=\frac{\sigma}{L}
$$

It can be written:

$$
f_{\mathrm{H}}=\frac{v}{2 \pi} \cdot \sqrt{\frac{\sigma^{0.75}}{L(1.367 d+0.5173 l)}}
$$

which is the formula used to obtain the Helmholtz resonance frequency of the synthetic jet actuator.

\subsection{Coupling Ratio in the Analysis of the Model of the Helmholtz Resonance Frequency of an SJ Actuator}

The model presented above was obtained based on the experiments performed using a wide but limited range of SJ actuator geometrical parameters. The graphical presentation of the M3 model compared with the M1 and M2 models (see Table 3) in the considered l/d range is presented in Figure 15. The M3 model is shown with a parameter $\sigma$ equal to the extreme values of the investigated SJ actuator geometry range. 


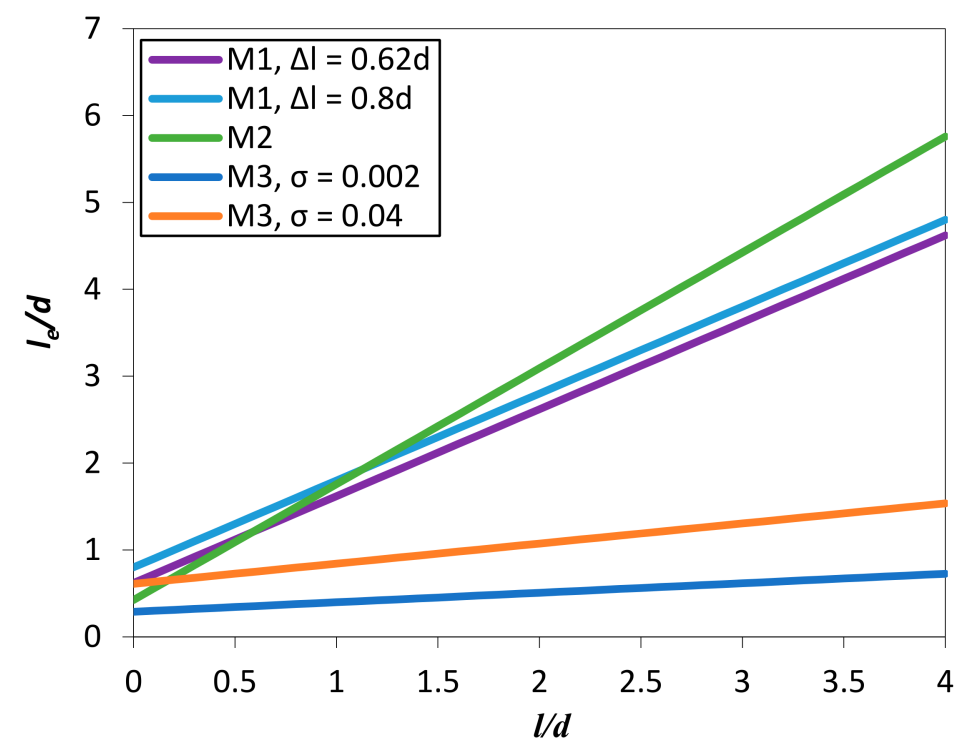

Figure 15. The dependence of the dimensionless effective length as a function of the dimensionless orifice length.

As can be seen, the presented model differs significantly from the M1 and M2 models, raising the question of whether another parameter affects the frequency. Thus, an additional parameter that influences the Helmholtz resonance frequency of the SJ actuator was taken into account. This parameter is the coupling ratio $C R$, which represents the ratio of the air stiffness enclosed within the cavity to the diaphragm stiffness [23]. It is given by:

$$
C R=\left(\frac{\omega_{p}}{\omega_{D}}\right)^{2}
$$

where $\omega_{D}$ represents the structural angular frequency of the diaphragm, and is given by:

$$
\omega_{D}=\sqrt{\frac{k_{D}}{m_{D}}}
$$

where $k_{D}$ is the equivalent spring stiffness of the diaphragm and $m_{D}$ is the diaphragm mass.

In addition, $\omega_{p}$ is the natural frequency of the pneumatic spring made of the air in the cavity and of the diaphragm mass $m_{D}$ [18]. It is defined as:

$$
\omega_{p}=\sqrt{\frac{\kappa \cdot A_{D}^{2} \cdot p_{a}}{V \cdot m_{D}}}
$$

where $A_{D}$ is a diaphragm wall area.

If $C R$ takes small values, the system of the diaphragm dynamics is decoupled from the acoustic oscillator [23]. Then, the Helmholtz and the diaphragm resonance frequency positions are far apart [24] and the uncoupled case occurs. For larger values of $C R$, the dependence of the centerline characteristic velocity of the SJ actuator on the excitation frequency has a form similar to that of Figure 5, and the coupled case occurs.

Based on the characteristics of the STX W.18.200.8.FGX-type loudspeaker used in the present investigations, the $C R$ parameter was obtained for the investigated geometries of the SJ actuator. The coupling ratio was changed from about $C R=20$ for the largest cavity length, to about $C R=100$ for the smallest cavity length. These findings indicate that coupling occurred in the considered system, and a single peak of characteristic velocity emerged, which was mainly dominated by the diaphragm resonance, as shown in Figure 5.

Figure 15 compares the obtained M3 model with the literature data, and shows a large discrepancy. This may be due to the large value of $C R$ in the case considered. Model M1, 
with $\Delta l=0.62 d$, was used by researchers [23] for investigations of the frequency response of SJ actuators. The authors obtained a good agreement between the numerical simulations and the experimental and analytical findings. In their tested cases, the CR ratio ranged from 0.04 to 1.88. In addition, the specifications of the investigated SJ actuators quoted in [15] enabled estimation of the $C R$ parameter, which had a value of about 3 . In this case, the experimental results were consistent with M2 model.

Based on the above considerations, it can be assumed that the type of SJ actuator system considered (uncoupled or coupled) has a significant impact on the modeling of the Helmholtz resonance frequency.

\section{Conclusions}

Loudspeaker synthetic jet actuators were tested using 108 various geometrical configurations. The experiment was performed to determine the impact of SJ geometry on the Helmholtz resonance frequency. Geometrical parameters of the SJ actuator-orifice diameter, orifice length, and cavity volume-were changed within a wide range. An additional geometric dimensionless parameter representing a ratio of the orifice cross-section area to the cross-section area of the cavity was introduced. The investigated cases of the SJ actuator were characterized by a high $C R$ parameter.

The dependences of electrical and flow parameters that characterize the considered synthetic jet actuators, as a function of the excitation frequency, were also identified.

Based on the obtained experimental results, an improved version of the classical model of the Helmholtz resonance frequency was derived. The model provides valuable insights into the behavior of SJ actuators.

Based on the research conducted and the obtained findings, some conclusions can be formulated:

- The Helmholtz resonance frequency can be determined from measurements of electrical parameters or measurements of the air velocity. However, due to the higher precision and greater repeatability of electrical measurements in relation to air velocity measurements with the use of constant temperature anemometry, the first method appears to be more appropriate.

- The resonance frequencies do not depend on the actuator supply voltage in the considered range of effective voltages.

- There is a decrease in $f_{H}$ with an increase in $V$, in the cases of constant $d$ or $l$ values. In addition, the Helmholtz resonance frequency increases as the orifice diameter increases at a constant value of the cavity volume and decreases as the orifice length increases.

- The additive length $\Delta l$ in the effective orifice length $l_{e}$ is a function not only of the orifice diameter, but also of the orifice length $l$ and the surface ratio $\sigma$.

- The obtained investigation results enabled the determination of an improved model for the Helmholtz resonance frequency of a synthetic jet actuator.

- The model obtained is valid in the case of SJ actuators characterized by large values of the coupling ratio.

The results of the conducted research represent a step towards the development of practical applications of loudspeaker-driven SJ actuators. The obtained knowledge about the Helmholtz resonance frequency can be of significance in SJ applications in cooling systems due to its impact on SJ actuator energetic efficiency and, consequently, heat transfer intensity.

Author Contributions: Conceptualization, P.G. and J.W.; methodology, P.G., J.W. and M.K.; software, validation, formal analysis, P.G., J.W. and M.K.; investigation, P.G.; resources, J.W. and P.G.; writingoriginal draft preparation, J.W.; writing-review and editing, J.W., P.G. and M.K.; visualization, P.G. and M.K.; supervision, J.W.; project administration, funding acquisition, P.G. All authors have read and agreed to the published version of the manuscript.

Funding: This work was supported by the National Center for Research and Development, Poland Grant No.: LIDER/6/0024/L-10/18/NCBR/2019. 
Institutional Review Board Statement: Not applicable.

Informed Consent Statement: Not applicable.

Data Availability Statement: Some or all data generated or used during the study are available from the corresponding author by request.

Conflicts of Interest: The authors declare no conflict of interest.

\section{Nomenclature}

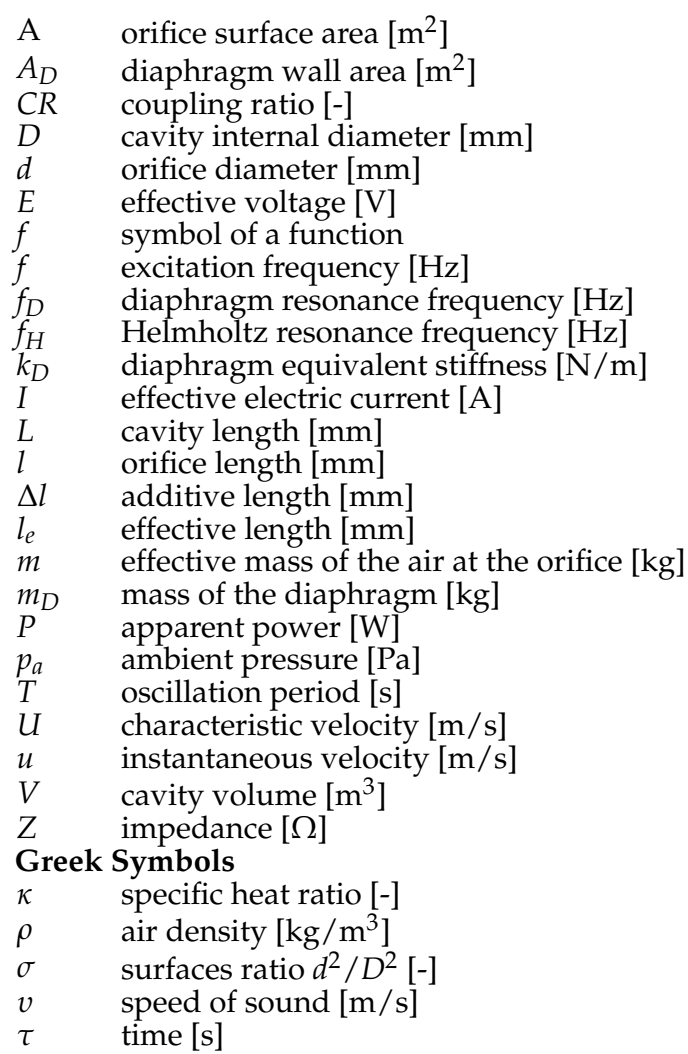

\section{References}

1. Arshad, A.; Jabbal, M.; Yan, Y. Synthetic jet actuators for heat transfer enhancement-A critical review. Int. J. Heat Mass Transf. 2020, 146, 118815. [CrossRef]

2. Krishan, G.; Aw, K.C.; Sharma, R.N. Synthetic jet impingement heat transfer enhancement-A review. Appl. Therm. Eng. 2019, 149, 1305-1323. [CrossRef]

3. Smyk, E.; Gil, P.; Gałek, R.; Przeszłowski, Ł. Acoustic and flow aspects of novel synthetic jet actuator. Actuators 2020, 9, 100. [CrossRef]

4. Smyk, E.; Wilk, J.; Markowicz, M. Synthetic Jet Actuators with the Same Cross-Sectional Area Orifices-Flow and Acoustic Aspects. Appl. Sci. 2021, 11, 4600. [CrossRef]

5. James, R.D.; Jacobs, J.W.; Glezer, A. A round turbulent jet produced by an oscillating diaphragm. Phys. Fluids 1996, 8, 2484-2495. [CrossRef]

6. Kral, L.D.; Donovan, J.F.; Cain, A.B.; Cary, A.W. Numerical simulation of synthetic jet actuators. In Proceedings of the 4th Shear Flow Control Conference, Snowmass Village, CO, USA, 29 June-2 July 1997.

7. Smith, B.L.; Glezer, A. The formation and evolution of synthetic jets. Phys. Fluids 1998, 10, 2281-2297. [CrossRef]

8. Guy, Y.; McLaughlin, T.; Morrow, J. Velocity measurements in a synthetic jet. In Proceedings of the 39th Aerospace Sciences Meeting and Exhibit, Reno, NV, USA, 8-11 January 2001. [CrossRef]

9. Guy, Y.; McLaughlin, T.; Albertson, J.A. Effect of geometric parameters on the velocity output of a synthetic jet actuator. In Proceedings of the 40th AIAA Aerospace Sciences Meeting \& Exhibit, Reno, NV, USA, 14-17 January 2002. [CrossRef]

10. Gil, P.; Smyk, E. Synthetic jet actuator efficiency based on the reaction force measurement. Sens. Actuators A Phys. 2019, 295, 405-413. [CrossRef]

11. Chaudhari, M.; Verma, G.; Puranik, B.; Agrawal, A. Frequency response of a synthetic jet cavity. Exp. Therm. Fluid Sci. 2009, 33, 439-448. [CrossRef] 
12. Gil, P.; Strzelczyk, P. Performance and efficiency of loudspeaker driven synthetic jet actuator. Exp. Therm. Fluid Sci. 2016, 76, 163-174. [CrossRef]

13. Kordík, J.; Trávníček, Z. Optimal diameter of nozzles of synthetic jet actuators based on electrodynamic transducers. Exp. Therm. Fluid Sci. 2017, 86, 281-294. [CrossRef]

14. Gallas, Q.; Mathew, J.; Kaysap, A.; Holman, R.; Nishida, T.; Carrol, B.; Sheplak, M.; Cattafesta, L. Lumped Element Modeling of Piezoelectric-Driven Synthetic Jet Actuators. In Proceedings of the 40th AIAA Aerospace Sciences Meeting \& Exhibit, Reno, NV, USA, 14-17 January 2002. [CrossRef]

15. Gallas, Q.; Holman, R.; Nishida, T.; Carrol, B.; Sheplak, M.; Cattafesta, L. Lumped Element Modeling of Piezoelectric-Driven Synthetic Jet Actuators. AIAA J. 2003, 41, 240-247. [CrossRef]

16. Gallas, Q. Modeling and development of synthetic jet actuators in flow separation control application. Solid Mech. Its Appl. 2008, 7, 361-364. [CrossRef]

17. Sharma, R.N. Some insights into synthetic jet actuation from analytical modelling. In Proceedings of the 16th Australasian Fluid Mechanics Conference, Brisbane, Australia, 3-7 December 2007.

18. Sharma, R.N. Fluid-dynamics-based analytical model for synthetic jet actuation. AIAA J. 2007, 45, 1841-1847. [CrossRef]

19. Gil, P.; Wilk, J.; Smusz, R.; Gałek, R. Centerline heat transfer coefficient distributions of synthetic jets impingement cooling. Int. J. Heat Mass Transf. 2020, 160. [CrossRef]

20. Greco, C.S.; Paolillo, G.; Ianiro, A.; Cardone, G.; de Luca, L. Effects of the stroke length and nozzle-to-plate distance on synthetic jet impingement heat transfer. Int. J. Heat Mass Transf. 2018, 117, 1019-1031. [CrossRef]

21. Tang, H.; Zhong, S. Lumped element modelling of synthetic jet actuators. Aerosp. Sci. Technol. 2009, 13, 331-339. [CrossRef]

22. Persoons, T. General reduced-order model to design and operate synthetic jet actuators. AIAA J. 2012, 50, 916-927. [CrossRef]

23. De Luca, L.; Girfoglio, M.; Coppola, G. Modeling and experimental validation of the frequency response of synthetic jet actuators. AIAA J. 2014, 52, 1733-1748. [CrossRef]

24. Gomes, L.D.; Crowther, W.J.; Wood, N.J. Towards a practical piezoceramic diaphragm based synthetic jet actuator for high subsonic applications-Effect of chamber and orifice depth on actuator peak velocity. In Proceedings of the 3rd AIAA Flow Control Conference, San Francisco, CA, USA, 5-8 June 2006.

25. Chiatto, M.; Capuano, F.; Coppola, G.; De Luca, L. LEM characterization of synthetic jet actuators driven by piezoelectric element: A review. Sensors 2017, 17, 1216. [CrossRef] [PubMed]

26. Persoons, T.; Cressall, R.; Alimohammadi, S. Validating a reduced-order model for synthetic jet actuators using CFD and experimental data. Actuators 2018, 7, 67. [CrossRef]

27. Rossing, T.D. Springer Handbook of Acoustics; Springer Science+Bussiness Media: New York, NY, USA, 2007. 